\title{
Telocytes in pleura: two- and three-dimensional imaging by transmission electron microscopy
}

\author{
Mihail E. Hinescu • Mihaela Gherghiceanu • \\ Laura Suciu • Laurentiu M. Popescu
}

Received: 24 September 2010 / Accepted: 18 November 2010 /Published online: 22 December 2010

(C) The Author(s) 2010. This article is published with open access at Springerlink.com

\begin{abstract}
Information about the ultrastructure of connective (interstitial) cells supporting the pleural mesothelium is scarce. Our aim has been to examine whether telocytes (TCs) are present in pleura, as in epicardium and mesentery. TCs are a distinct type of cell, characterized by specific prolongations named telopodes (Tp). We have used transmission electron microscopy (TEM) and electron tomography (ET) to determine whether ultrastructural diagnostic criteria accepted for TCs are fulfilled by any of the cell subpopulations existing in the sub-mesothelial layer in mouse and human pleura. TCs have been identified with TEM by their characteristic prolongations. Tp appear long and moniliform, because of the alternation of podomeres (thin segments of less than $0.2 \mu \mathrm{m}$ ) and podoms (small dilations accommodating caveolae, mitochondria, and endoplasmic reticulum). Tp ramifications follow a dichotomic pattern and establish specialized cell-to-cell junctional complexes. TCs, via their
\end{abstract}

Mihail E. Hinescu and Mihaela Gherghiceanu contributed equally to this study.

This work was supported by CNCSIS-UEFISCSU (project number PNII - IDEI 957/2008) and partially by the Sectorial Operational Programme Human Resources Development (SOP HRD) financed by the European Social Fund and by the Romanian Government under contract number POSDRU/89/1.5/S/64109.

Electronic supplementary material The online version of this article (doi:10.1007/s00441-010-1095-0) contains supplementary material, which is available to authorized users.

M. E. Hinescu $\cdot$ L. Suciu $\cdot$ L. M. Popescu

Department of Cellular and Molecular Medicine,

"Carol Davila" University of Medicine and Pharmacy,

P.O. Box 35-29, Bucharest 35, Romania

M. E. Hinescu • M. Gherghiceanu $\cdot$ L. Suciu $・$ L. M. Popescu $(\bowtie)$

"Victor Babeş" National Institute of Pathology,

Bucharest, Romania

e-mail: 1popescu@jcmm.org
$\mathrm{Tp}$, seem to form an interstitial network beneath the mesothelium, covering about two-thirds of the abluminal mesothelial layer. ET has revealed complex junctional structures and tight junctions connecting pleural TCs, and small vesicles at this level in Tp. Thus, pleural TCs share significant similarities with TCs described in other serosae. Whether TCs are a (major) player in mesothelial-cell-induced tissue repair remains to be established. Nevertheless, the extremely long thin $\mathrm{Tp}$ and complex junctional structures that they form and the release of vesicles (or exosomes) indicate the participation of TCs in long-distance homo- or heterocellular communication.

Keywords Telocytes $\cdot$ Telopodes $\cdot$ Pleura $\cdot$ Electron tomography · Tight junctions · Mouse $(\mathrm{C} 57 \mathrm{BL} / 6) \cdot$ Human

\section{Introduction}

We previously described a new type of cell, which became known as the "interstitial Cajal-like cell" (acronym ICLC), based on the finding that these cells seemed, at first glance, similar to the well-known interstitial cell of Cajal (ICC) found in the gastro-intestinal tract. We described ICLCs in various cavitary (fallopian tube: Popescu et al. 2005a; uterus: Ciontea et al. 2005; Popescu et al. 2006c; gallbladder: Hinescu et al. 2007; heart: Hinescu and Popescu 2005; Hinescu et al. 2006; Popescu et al. 2006a; Mandache et al. 2007; Gherghiceanu et al. 2008; Kostin and Popescu 2009) and non-cavitary (pancreas: Popescu et al. 2005c; mammary gland: Gherghiceanu and Popescu 2005; placenta: Suciu et al. 2007, 2010) organs. However, little by little, it became clear that the ultrastructure of ICLC was (completely) different from that of ICC, and that the difference between these cells was not only semantic, as 

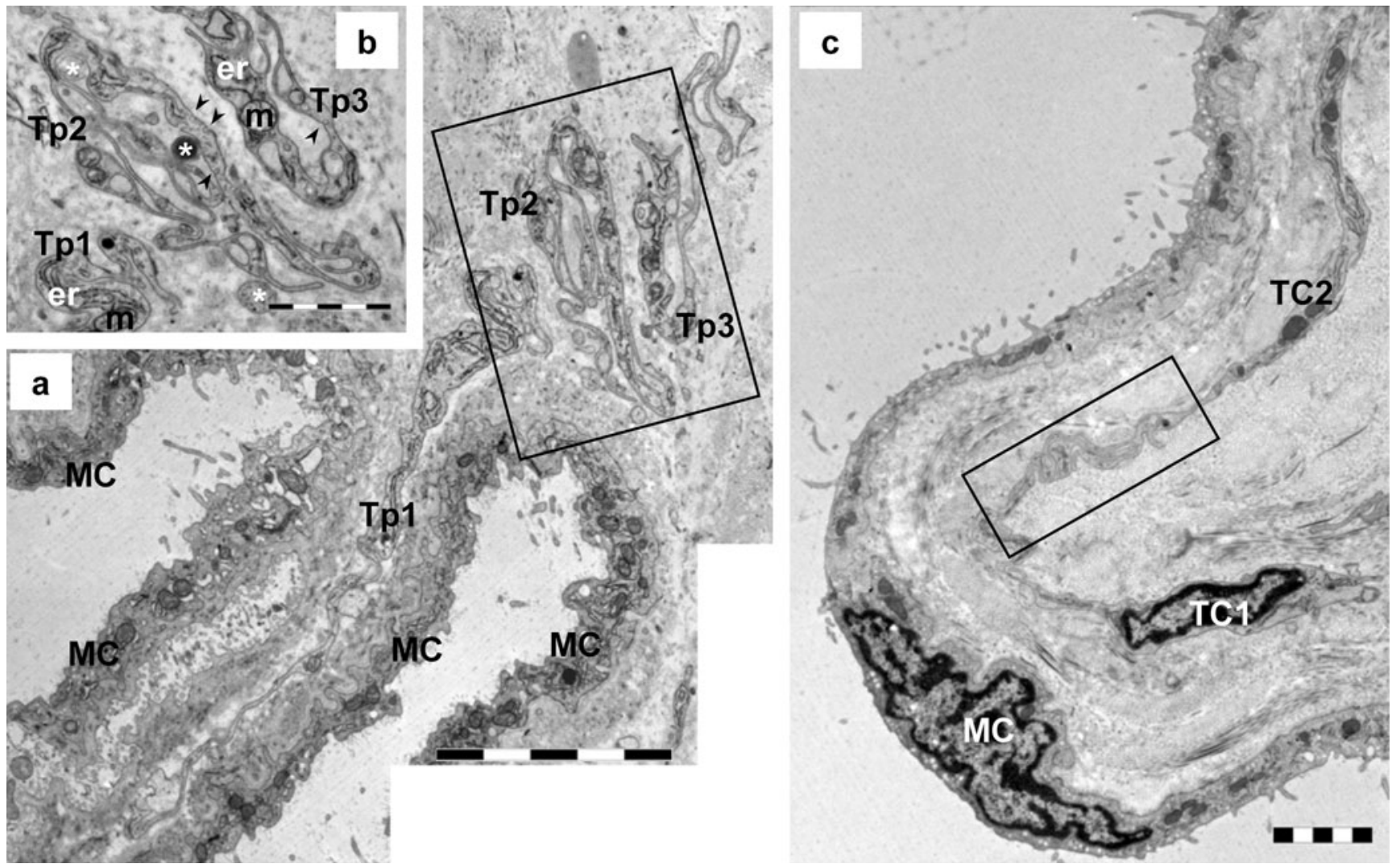

Fig. 1 Transmission electron microscopy (TEM) images of two serial sections of mouse parietal pleura to illustrate the long telopodes $(T p)$ and their sinuous trajectory. a Tp (Tp1: $20 \mu \mathrm{m} ; T p 2: 24 \mu \mathrm{m}$; $T p 3: 20 \mu \mathrm{m})$ have a convoluted contour suggesting their capacity to compensate for changes in length attributable to pleural expansion $(M C$ mesothelial cells). b TEM image of the adjacent section showing details of the Tp from the boxed area in a. Tp have thin segments (podomeres)

they have different ultrastructure and immunophenotype and therefore are probably functionally distinct (Popescu and Faussone-Pellegrini 2010; free access data is available on www.telocytes.com). Hence, we coined the terms telocyte (TC) for these cells and telopodes (Tp) for their extremely long but thin prolongations in order to prevent further confusion with other interstitial (stromal) cells (e.g., fibroblasts/fibrocytes, mesenchymal cells, or myofibroblasts). The concept of TCs was rapidly adopted by other laboratories (Bani et al. 2010; Cantarero et al. 2010; Faussone-Pellegrini and Bani 2010; Kostin 2010; Zhou et al. 2010)

Little information exists concerning the ultrastructure of the sub-epithelial tissue of serosae (Carter et al. 2007), including pleura (Hammar 2008). Despite their simple fine morphology, serosae share not only a common embryological origin from splanchnopleural mesenchyme (Lie-Venema et al. 2007; Di Meglio et al. 2009; Gittenberger-de Groot et al. 2010), but also similar functions, based on cytoarchitectural similarities. However, the precise details of interstitial cells composing serosae seem incompletely explored, since a new type of cell has been indentified in omentum (Sakurai et alternating with dilatations (podoms), which accommodate mitochondria $(m)$, endoplasmic reticulum $(e r)$, and caveolae (arrowheads). Note the shed vesicles (asterisks) in close proximity to Tp. c TEM image of the telocyte network (TC1: $14 \mu \mathrm{m}$ long, TC2: $15 \mu \mathrm{m}$ long) beneath the mesothelial cell layer $(M C)$. The boxed area was selected for electron tomography (see Fig. 5). Bars $5 \mu \mathrm{m}$ (a), $2 \mu \mathrm{m}$ (b, c)

al. 2001), mesentery (Hinescu et al. 2008), and epicardium (Suciu et al. 2009; Gherghiceanu and Popescu 2009, 2010; Popescu et al. 2009, 2010a, 2010b).

Here, we present evidence that ultrastructural criteria (Popescu and Faussone-Pellegrini 2010) usually applied to diagnose TCs are fulfilled by a sub-population of cells present in mouse and human pleura, in the thin submesothelial layer. Despite technology having matured to the point at which the application of electron tomography (ET) specimens in plastic sections has been achievable for almost a decade (McEwen and Marko 2001), little information is available about the cells in tissue (Barcena and Koster 2009). We have used ET in this study in order to examine the particular ultrastructure of TCs with emphasis on $\mathrm{Tp}$ connections.

\section{Materials and methods}

Mouse parietal pleura samples were obtained from four 8month-old C57BL/6 mice. Human parietal pleura samples 
Fig. 2 TEM images of submesothelial telocytes $(T C)$ from mouse parietal pleura. a Telopode $(T p)$ lying next to a mononuclear cell $(\mathrm{Mo})$. Small shed vesicles (arrows) can also be observed. The cellular body of TC is visible in the inset (MC mesothelial cell). b Note the stromal synapse (white arrows) between a telopode $(T p)$ and a macrophage. c A podom, the dilated segment of a telopode, accommodates mitochondria $(m)$, endoplasmic reticulum (er), and caveolae (arrowhead). Bars $5 \mu \mathrm{m}$ (a, inset), $1 \mu \mathrm{m}$ (b), $0.5 \mu \mathrm{m}(\mathbf{c})$
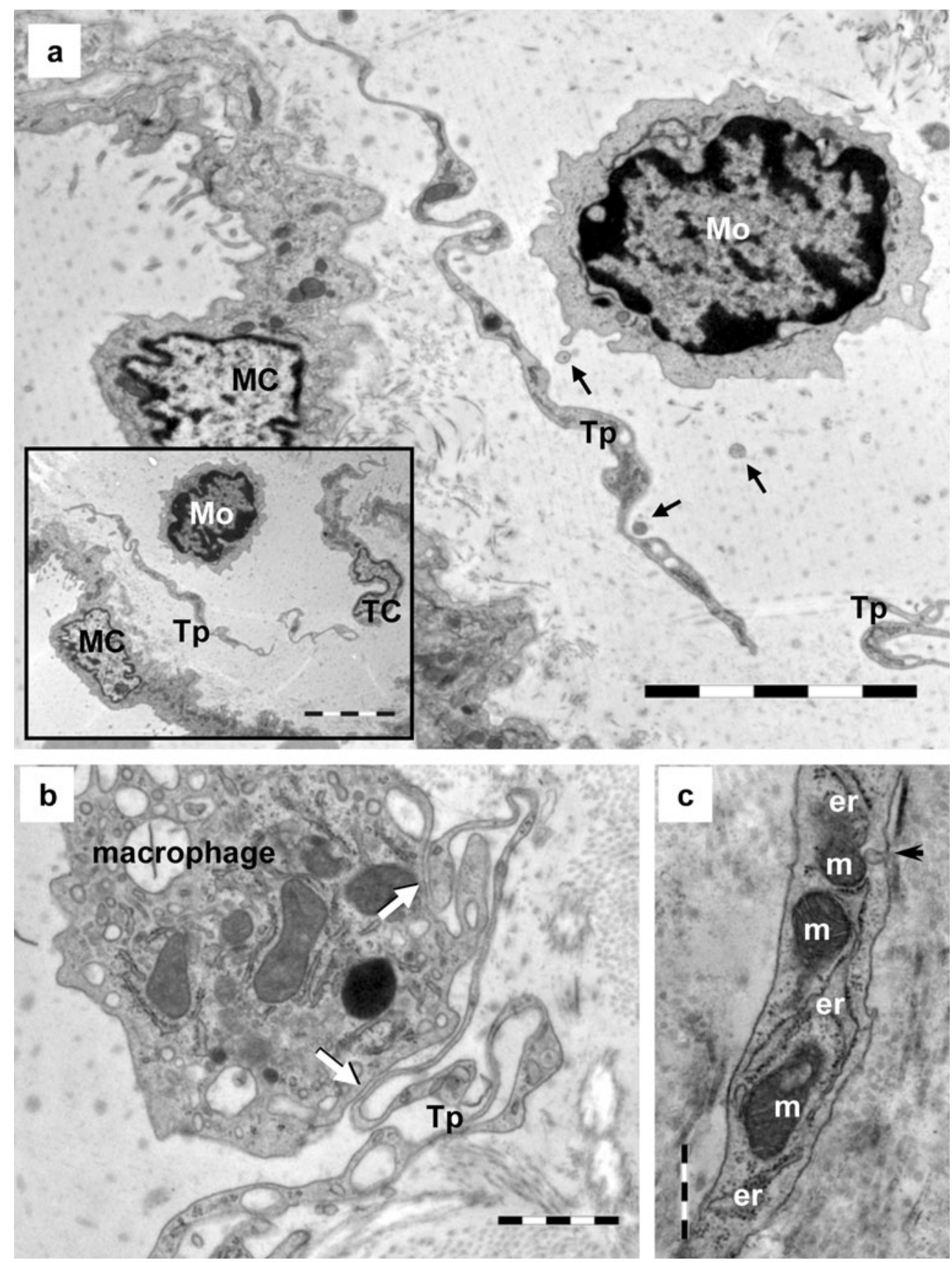

were obtained from two patients undergoing surgery for non-neoplastic lung diseases. This study was performed with institutional ethical committee approval.

Transmission electron microscopy Transmission electron microscopy (TEM) was performed on small fragments from parietal pleura processed according to a routine Eponembedding procedure, as previously described (Mandache et al. 2007; Hinescu et al. 2008). Thin sections (about $60 \mathrm{~nm}$ ) were examined with a Morgagni 286 transmission microscope (FEI Company, Eindhoven, The Netherlands) at $60 \mathrm{kV}$. Digital electron micrographs were recorded with a MegaView III charge-coupled device (CCD) by using iTEM-
SIS software (Olympus, Soft Imaging System, Münster, Germany). Some TEM images were digitally colored by Adobe Photoshop CS3 in order to highlight TCs.

Electron microscope tomography ET was performed by using a Tecnai G2 Spirit BioTwin transmission electron microscope with single-tilt specimen holder (FEI Company) at $100 \mathrm{kV}$. Electron tomographic data sets were recorded with a MegaView G2 CCD camera (Olympus) in ET mode on 300-nm-thick sections of Epon-embedded mouse parietal pleura. Tomographs were acquired at 1 degree angular increments from $-65^{\circ}$ to $+65^{\circ}$ about an axis perpendicular to the optical axis of the microscope, at a 


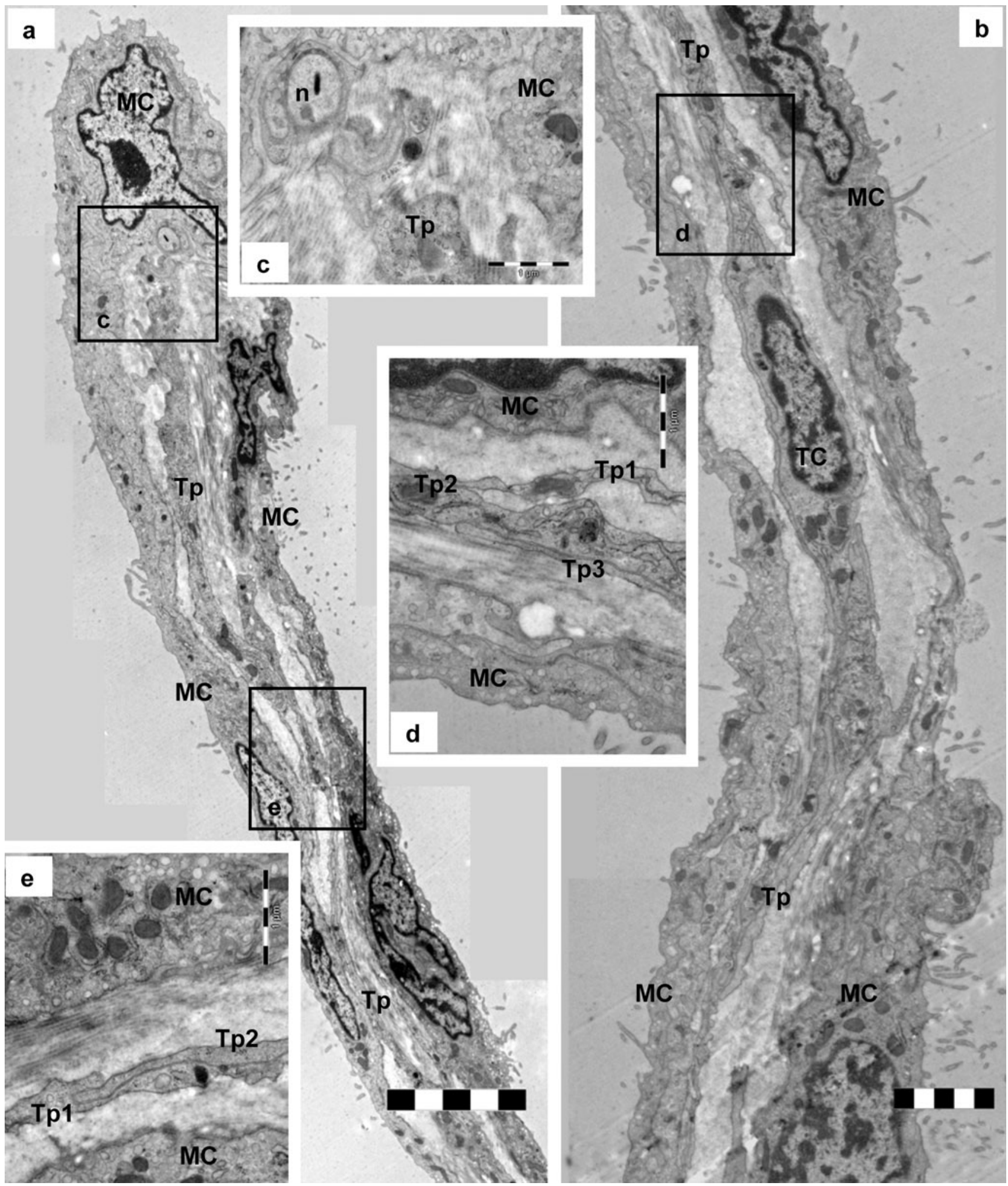

Fig. 3 a, b TEM images of telocytes $(T C)$ and their overlapping telopodes $(T p)$ that reinforce the mesothelial cells $(M C)$ at the level of folds formed by mouse parietal pleura. $\mathbf{c}-\mathbf{e}$ Higher magnifications of boxed areas in $\mathbf{a}, \mathbf{b}$. $\mathbf{c}$ Telopodes $(T p)$ in close vicinity of nerve ending (n) beneath mesothelial cells $(M C)$. d, e Telopodes (Tp1-3 in d, Tp1, $T p 2$ in e) can be seen overlapping each other in the mesothelial folds. Bars $5 \mu \mathrm{m}(\mathbf{a}), 2 \mu \mathrm{m}(\mathbf{b}), 1 \mu \mathrm{m}(\mathbf{c}-\mathbf{e})$ 
Fig. 4 Digitally colored transmission electron micrographs of human parietal pleura with the telocytes and telopodes in blue. a Telocyte (TC) and telopodes ( $T p)$ border the mesothelial cell layer $(M C)$. b A telocyte $(T C)$ in the sub-mesothelial space in close vicinity to a mast cell. Numerous telopodes $(T p)$ can be seen between the collagen and elastin $(E)$ fibers. c Higher magnification of the boxed area in $\mathbf{b}$ showing that a telocyte $(T C)$ is connected by an electron-dense structure (black arrow) with a telopode of another telocyte. Note the apposition of the same telocyte with the mast cell (white arrow) in a stromal synapse. Bars $5 \mu \mathrm{m}$ (a), $2 \mu \mathrm{m}$ (b), $1 \mu \mathrm{m}$ (c)
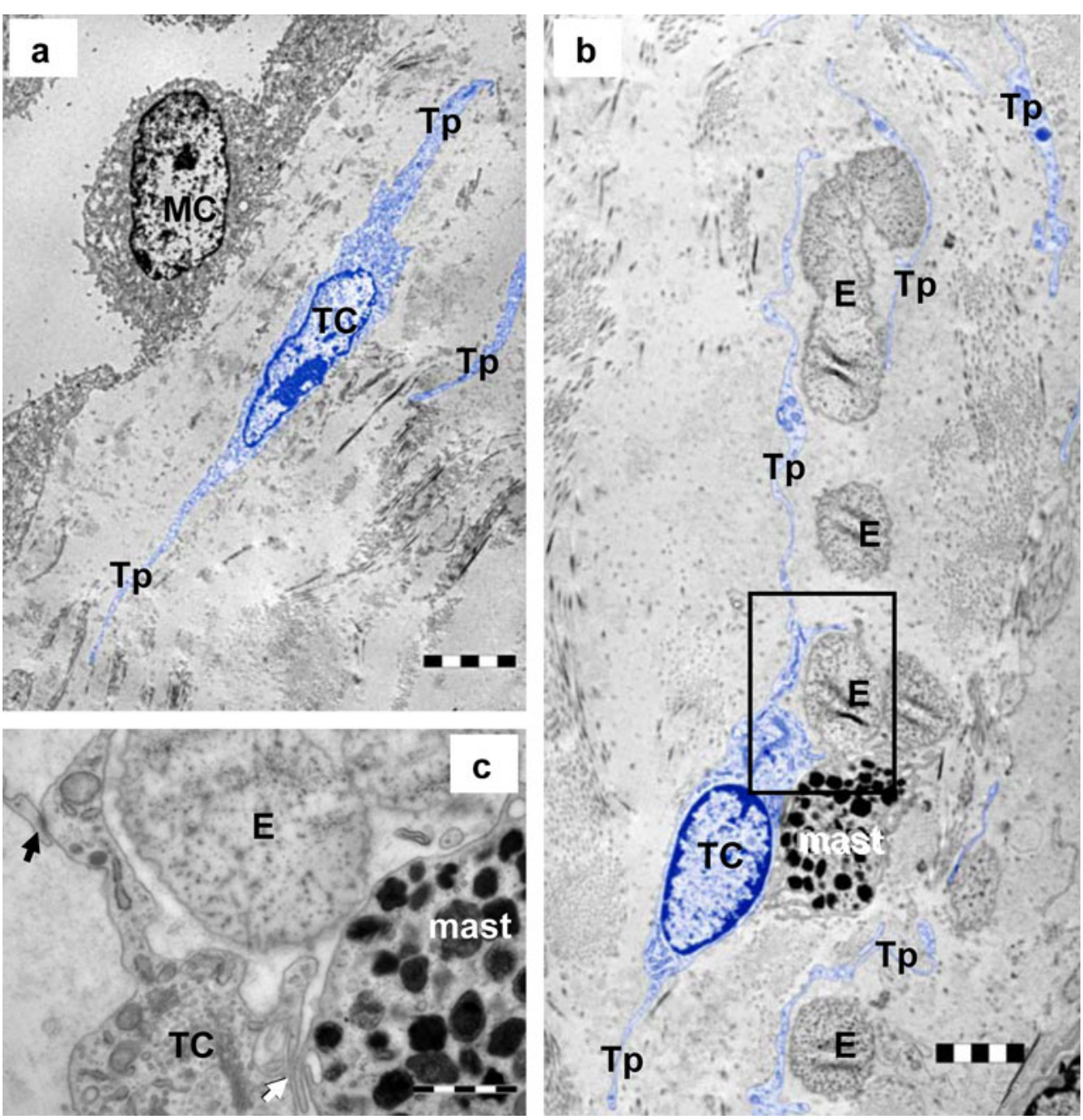

magnification of $36,000 \times$. After data alignment, the data sets were reconstructed into a three-dimensional (3D) volume (data collection, reconstruction, and visualization) by using Xplore3D Tomography Suite software (FEI Company). Amira 5.0.1 software (Visage Imaging, Berlin, Germany) was used for 3D imaging.

\section{Results}

\section{Electron microscopy}

Electron microscopy of 60 -nm thin sections revealed that the main cellular component of interstitial space beneath the mesothelial layer of mouse parietal pleura consisted of numerous TCs (Figs. 1, 2, 3) and few mononuclear cells (Fig. 2a), macrophages (Fig. 2b), and nerve endings (Fig. 3) in a slightly collagenic extracellular matrix. In human parietal pleura, the sub-mesothelial space contained numerous TCs (Fig. 4), mononuclear cells, macrophages, mast cells, and nerve endings in a matrix composed of layers of collagen and elastic fibers (Fig. 4). TCs seemed to form an interstitial network bordering about two-thirds of the abluminal mesothelial layer (Figs. 1, 2, 3, 4), especially at the level of small mesothelial folds (Figs. 1a, 3).

Pleural TCs showed typical features: a small oval-shaped cell body surrounded by a ring of cytoplasm (Figs. 1c, 2a, inset, $3 \mathrm{~b}, 4 \mathrm{a}, \mathrm{b})$ and 2-4 extremely long $(15-30 \mu \mathrm{m})$ but thin prolongations named telopodes (Tp; Figs. 1, 2, 3, 4). The moniliform aspect of $\mathrm{Tp}$ resulted from the alternation of two types of segments: podomeres (thin segments of $\sim 50 \mathrm{~nm}$ and therefore below the resolving power of light microscopy) and podoms (dilations of $\sim 150-300 \mathrm{~nm}$ ) accommodating caveolae, 1-2 mitochondria, and elements of smooth and/or rough endoplasmic reticulum (Figs. 1b, 2c). Functionally, the trio caveolae/mitochondria/endoplasmic reticulum corresponded to " $\mathrm{Ca}^{2+}$-uptake/release units" (Popescu et al. 2006b; Gherghiceanu and Popescu 2007).

Tp showed characteristic dichotomous branching pattern (Fig. 3d) with a sinuous trajectory (Fig. 1a, b) that allowed the accommodation of long $\mathrm{Tp}$ in a small space (e.g., 20-25 $\mu \mathrm{m}$ long Tp compressed in less than $2 \mu \mathrm{m}$ ). In order to evaluate the extension potential of the $\mathrm{Tp}$, a convolution index was 
Fig. 5 TEM (a) and electron tomography $(E T ; \mathbf{b}-\mathbf{e})$ of telocyte junctional complex in mouse parietal pleura. a TEM image (the boxed area is shown at higher magnification in Fig. 1c). Note the small cortical densities (white arrows) between the plasma membranes of the telopodes and a tight junction (double arrows). Telopodes $(T p 1, T p 2)$ are connected through a "plug and socket" assembly. A vesicle (black arrow) is visible in the Tp2 telopodes. b Tomographic slice (36/ 71 digital sections) from the ET reconstruction showing four electron-dense structures (white arrows) connecting the telopodes in the "plug and socket" assembly. Two other connecting structures (arrowheads) with another telopode are visible at the periphery of the reconstructed volume. c Top view of the $3 \mathrm{D}$ isosurface reconstruction showing four junctions (1-4), enhanced in red, connecting telopodes (yellow). d Oblique view of the junctional complex superimposed over a slice through the reconstruction showing the irregularities of junctional volumes. See also the electron tomography $3 \mathrm{D}$ volume in S1. e A lateral view of the three-dimensional reconstructed junctional volume from d. Bars $0.5 \mu \mathrm{m}(\mathbf{a}-\mathbf{c}), 0.2 \mu \mathrm{m}(\mathbf{d}, \mathbf{e})$
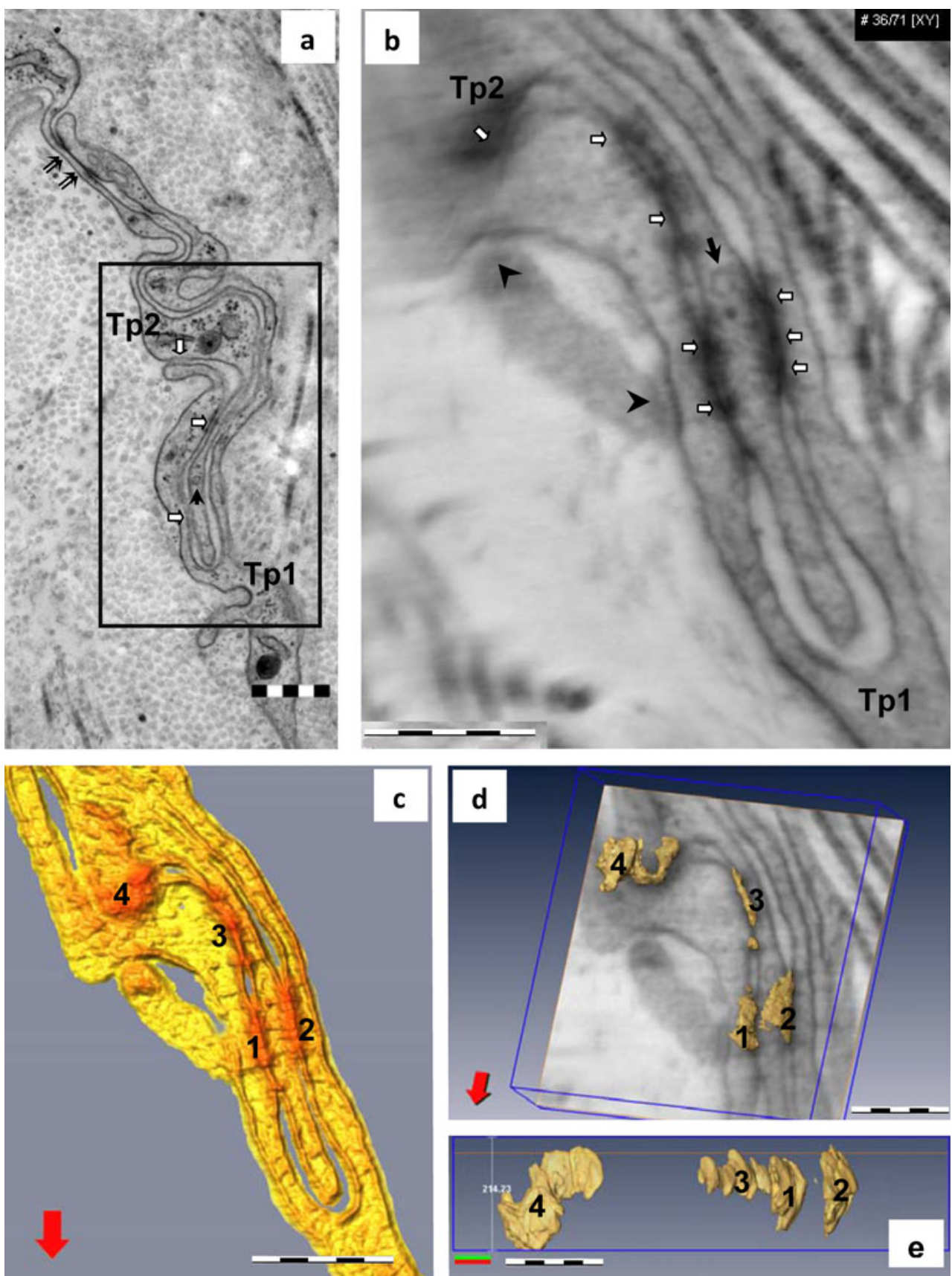

expressed as their actual length divided by the end-to-end distance in a straight line (Hinescu et al. 2007); a mean value of 7.5 was obtained.

TCs were in close vicinity to nerve endings (Fig. 3c) and established contacts with other interstitial immunoreactive cells (Figs. 2a, b, 4c) or other TCs (Figs. 1c, 3d, e, 4c) in the sub-mesothelial space. TEM showed that TCs formed a network, and that their intricate $\mathrm{Tp}$ were often connected through a "plug and socket" complex (Figs. 1c, 3e, 5a). TCs showed spot-like electron-dense structures on the cortical space of the Tp involved in the "plug and socket" connections and few tight junctions (Fig. 5a). To analyze these junctional complexes, we performed ET.
Electron tomography

ET $\left(0.5 \mu \mathrm{m}^{3}\right.$ volume $)$ of the "plug and socket" assembly connecting TCs (Figs. 5b-e, S1, S2) revealed the presence of composite junctions between $\mathrm{Tp}$. The junctional complex was composed of junctional plaques (four clear junctions of about $0.5 \mu \mathrm{m}$ long $/ 0.2 \mu \mathrm{m}$ wide are presented in Fig. $5 \mathrm{c}-\mathrm{e}$ ) alternating with free segments (about $0.5 \mu \mathrm{m}$ long). The junctional plaques showed anfractuous volumes (Figs. $5 \mathrm{~d}$, $\mathrm{e}, \mathrm{S} 1)$. The distances between cellular membranes of Tp were variable, with "fusion" points alternating with about 20-nm-wide gaps between membranes at the level of the junctional plaques (Figs. 6, S2). Small vesicles $(30-40 \mathrm{~nm})$ 
Fig. 6 Details of ET in TC junctional complex in mouse parietal pleura (black arrow vesicle visible in one telopode involved in the junctional complex). a Top view of the $3 \mathrm{D}$ isosurface reconstruction of junctions 1 and 2 from Fig. 5d shows an intercellular cleft (about $20 \mathrm{~nm}$ wide) between tight connecting lines (white arrows). b Cropped corner of the reconstructed volume showing the tight peripheral connecting lines (white arrows) in different planes. Bars $0.5 \mu \mathrm{m}$ (a), $0.2 \mu \mathrm{m}$ (b). See also the ET $3 \mathrm{D}$ volume in Fig. S2
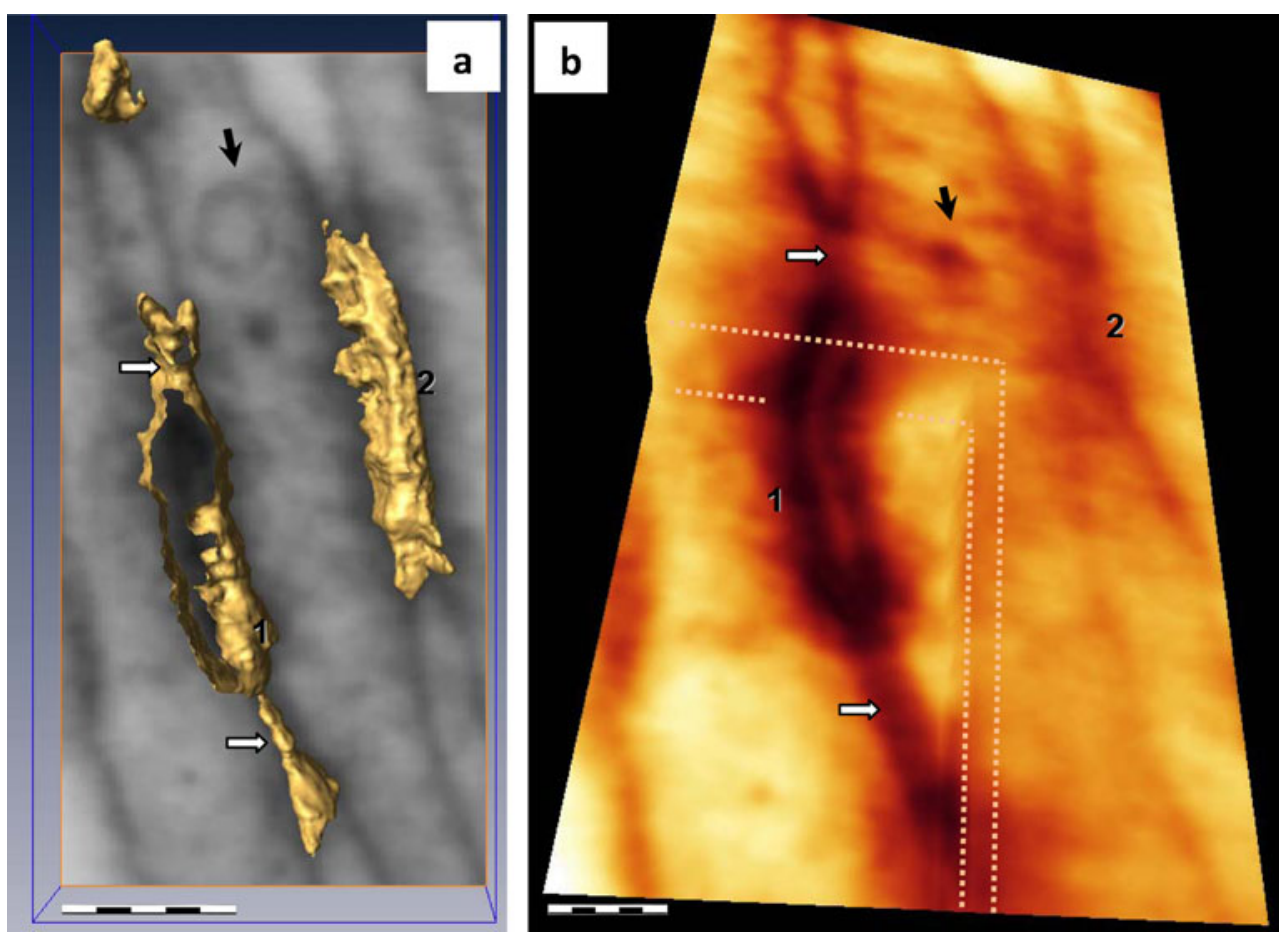

were present within the Tp placed in the center of "plug and socket" assembly (Figs. 5, 6).

\section{Discussion}

This paper establishes that telocytes are present not only in mesentery (Hinescu et al. 2008) and in epicardium (Suciu et al. 2009; Gherghiceanu and Popescu 2009, 2010; Popescu et al. 2009, 2010a), but also in mouse and human pleura, suggesting that TCs are a common cellular component of the serosae. From a teleological point of view, the presence of numerous fibroblasts in normal pleura (Carter et al. 2007) is unsuitable because the main function of fibroblasts is to produce collagen fibers, which are by definition nonextensible.

TEM has shown that pleural TCs lie close to nerve endings and immunoreactive interstitial cells (mononuclear cells, macrophages, mast cells). No apparent classical junctions have been observed in between these heterotypic cells, but rather stromal synapses (Popescu et al. 2005b). Of particular interest is that small shed vesicles or exosomes can often be observed in the intercellular space at the level of the stromal synapse suggesting that heterocellular communication might occur (Mathivanan et al. 2010). All these findings suggest that shed vesicles are involved in stromal synapses of TC heterocellular contacts with other interstitial cells, and that the tight junctions support TC homocellular connections.

The present study has revealed that pleural TCs are connected in a network through tight junctions situated at the level of "plug and socket" assembled telopodes (Figs. 5, 6). This elaborate connection between TCs, as revealed by ET, supports a previous hypothesis about long-distance intercellular signaling (Popescu and Faussone-Pellegrini 2010; Popescu et al. 2010b). Data presented in our ET study not only have revealed how difficult the mapping of the spatial distribution of $\mathrm{Tp}$ could be by using classical electron microscopy, but have also illustrated the complex interaction between $\mathrm{Tp}$. ET has made possible the examination of TC cellular ultrastructure, opening up perspectives for scrutinizing the 3D architecture of extremely thin and convoluted $\mathrm{Tp}$, which are suspected of playing a key role in cellular function.

In addition to the classical barrier function, the tight junction is emerging as a regulator of cell growth and differentiation and acts as a scaffolding platform for cell signaling and as a docking station for transport vesicles (Schneeberger and Lynch 2004). Moreover, recent studies have shown prominent clusters of proteins involved in vesicular trafficking and synaptic transmission functions at the tight junction domain (Tang 2006; Steed et al. 2010).

A recent study (Gherghiceanu and Popescu 2009) has suggested that TCs are involved in mesothelial renewal. TCs might guide the migration of mesenchymal cells into the mesothelial layer of the epicardium. We have not found such images in this study, but similar mesenchymal cells do indeed exist in close vicinity to TCs beneath the mesothelial layer (Fig. 2a). In view of this, the proposed ideas regarding the origin of regenerated mesothelial cells covering the surface of body cavities, the differentiation of mesothelial cells from macrophages, the proliferation of residual meso- 
thelial cells, or the origin of mesothelial cells from fibroblasts (Amari et al. 2002) should be re-examined, because TCs might be important players in mesothelial-cell-induced mesothelial repair. Moreover, the results presented here open doors for theories and new perspective concerning intercellular communication on the basis that "special" junctions have previously been described between mesenchymal cells (Wuchter et al. 2007; Franke et al. 2009).

Open Access This article is distributed under the terms of the Creative Commons Attribution Noncommercial License which permits any noncommercial use, distribution, and reproduction in any medium, provided the original author(s) and source are credited.

\section{References}

Amari M, Taguchi K, Iwahara M, Shibuya K, Naoe S (2002) Immunohistochemical and ultrastructural study on effect of fibroblast growth factor on transformation of fibroblasts to regenerated mesothelial cells. Med Electron Microsc 35:225233

Bani D, Formigli L, Gherghiceanu M, Faussone-Pellegrini MS (2010) Telocytes as supporting cells for myocardial tissue organization in developing and adult heart. J Cell Mol Med 14:2531-2538

Barcena M, Koster AJ (2009) Electron tomography in life science. Semin Cell Dev Biol 20:920-930

Cantarero CI, Luesma BMJ, Junquera EC (2010) Identification of telocytes in the lamina propria of rat duodenum: transmission electron microscopy. J Cell Mol Med. doi:10.1111/j.1582-4934.2010.01207.x

Carter D, True L, Otis CN (2007) Serous membranes. In: Mills SE (ed) Histology for pathologists. Lippincott, Williams \& Wilkins, Philadelphia, pp 554-556

Ciontea SM, Radu E, Regalia T, Ceafalan L, Cretoiu D, Gherghiceanu M, Braga RI, Malincenco M, Zagrean L, Hinescu ME, Popescu LM (2005) C-kit immunopositive interstitial cells (Cajal-type) in human myometrium. J Cell Mol Med 9:407-420

Di Meglio F, Castaldo C, Nurzynska D, Romano V, Miraglia R, Montagnani S (2009) Epicardial cells are missing from the surface of hearts with ischemic cardiomyopathy: a useful clue about the self-renewal potential of the adult human heart? Int $\mathrm{J}$ Cardiol 145:e44-e46

Faussone-Pellegrini MS, Bani D (2010) Relationships between telocytes and cardiomyocytes during pre- and post-natal life. J Cell Mol Med 14:1061-1063

Franke WW, Rickelt S, Barth M, Pieperhoff S (2009) The junctions that don't fit the scheme: special symmetrical cell-cell junctions of their own kind. Cell Tissue Res 338:1-17

Gherghiceanu M, Popescu LM (2005) Interstitial Cajal-like cells (ICLC) in human resting mammary gland stroma. Transmission electron microscope (TEM) identification. J Cell Mol Med 9:893-910

Gherghiceanu M, Popescu LM (2007) Electron microscope tomography: further demonstration of nanocontacts between caveolae and smooth muscle sarcoplasmic reticulum. J Cell Mol Med 11:1416-1418

Gherghiceanu M, Popescu LM (2009) Human epicardium: ultrastructural ancestry of mesothelium and mesenchymal cells. J Cell Mol Med 13:2949-2951

Gherghiceanu M, Popescu LM (2010) Cardiomyocyte precursors and telocytes in epicardial stem cell niche: electron microscope images. J Cell Mol Med 14:871-877

Gherghiceanu M, Hinescu ME, Andrei F, Mandache E, Macarie CE, Faussone-Pellegrini MS, Popescu LM (2008) Interstitial Cajal- like cells (ICLC) in myocardial sleeves of human pulmonary veins. J Cell Mol Med 12:1777-1778

Gittenberger-de Groot AC, Winter EM, Poelmann RE (2010) Epicardium-derived cells (EPDCs) in development, cardiac disease and repair of ischemia. J Cell Mol Med 14:1056-1060

Hammar SP (2008) Nonneoplastic pleural disease. In: Tomashefski JF Jr, Cagle PT, Farver CF, Fraire AE (eds) Dail and Hammar's pulmonary pathology, vol. 1. Nonneoplastic lung disease. Springer, New York, pp 1139-1173

Hinescu ME, Popescu LM (2005) Interstitial Cajal-like cells (ICLC) in human atrial myocardium. J Cell Mol Med 9:972-975

Hinescu ME, Gherghiceanu M, Mandache E, Ciontea SM, Popescu LM (2006) Interstitial Cajal-like cells (ICLC) in atrial myocardium: ultrastructural and immunohistochemical characterization. J Cell Mol Med 10:243-257

Hinescu ME, Ardeleanu C, Gherghiceanu M, Popescu LM (2007) Interstitial Cajal-like cells in human gallbladder. J Mol Histol 38:275-284

Hinescu ME, Popescu LM, Gherghiceanu M, Faussone-Pellegrini MS (2008) Interstitial Cajal-like cells in rat mesentery: an ultrastructural and immunohistochemical approach. J Cell Mol Med $12: 260-270$

Kostin S (2010) Myocardial telocytes: a specific new cellular entity. J Cell Mol Med 14:1917-1921

Kostin S, Popescu LM (2009) A distinct type of cell in myocardium: interstitial Cajal-like cells (ICLCs). J Cell Mol Med 13:295308

Lie-Venema H, Akker NM van den, Bax NA, Winter EM, Maas S, Kekarainen T, Hoeben RC, deRuiter MC, Poelmann RE, Gittenberger-de Groot AC (2007) Origin, fate, and function of epicardium-derived cells (EPDCs) in normal andabnormal cardiac development. ScienceWorldJournal 7:1777-1798

Mandache E, Popescu LM, Gherghiceanu M (2007) Myocardial interstitial Cajal-like cells (ICLC) and their nanostructural relationships with intercalated discs: shed vesicles as intermediates. J Cell Mol Med 11:1175-1184

Mathivanan S, Ji H, Simpson RJ (2010) Exosomes: extracellular organelles important in intercellular communication. J Proteomics. 73:1907-1920

McEwen BF, Marko MJ (2001) The emergence of electron tomography as an important tool for investigating cellular ultrastructure. Histochem Cytochem 49:553-564

Popescu LM, Faussone-Pellegrini MS (2010) Telocytes - a case of serendipity: the winding way from interstitial cells of Cajal (ICC), via interstitial Cajal-like cells (ICLC) to telocytes. J Cell Mol Med 14:729-740

Popescu LM, Ciontea SM, Cretoiu D, Hinescu ME, Radu E, Ionescu N, Ceausu M, Gherghiceanu M, Braga RI, Vasilescu F, Zagrean L, Ardeleanu C (2005a) Novel type of interstitial cell (Cajal-like) in human fallopian tube. J Cell Mol Med 9:479-523

Popescu LM, Gherghiceanu M, Cretoiu D, Radu E (2005b) The connective connection: interstitial cells of Cajal (ICC) and ICClike cells establish synapses with immunoreactive cells. Electron microscope study in situ. J Cell Mol Med 9:714-730

Popescu LM, Hinescu ME, Ionescu N, Ciontea SM, Cretoiu D, Ardelean C (2005c) Interstitial cells of Cajal in pancreas. J Cell Mol Med 9:169-190

Popescu LM, Gherghiceanu M, Hinescu ME, Cretoiu D, Ceafalan L, Regalia T, Popescu AC, Ardeleanu C, Mandache E (2006a) Insights into the interstitium of ventricular myocardium: interstitial Cajal-like cells (ICLC). J Cell Mol Med 10:429-458

Popescu LM, Gherghiceanu M, Mandache E, Cretoiu D (2006b) Caveolae in smooth muscles: nanocontacts. J Cell Mol Med 10:960-990

Popescu LM, Vidulescu C, Curici A, Caravia L, Simionescu AA, Ciontea SM, Simion S (2006c) Imatinib inhibits spontaneous 
rhythmic contractions of human uterus and intestine. Eur J Pharmacol 546:177-181

Popescu LM, Gherghiceanu M, Manole CG, Faussone-Pellegrini MS (2009) Cardiac renewing: interstitial Cajal-like cells nurse cardiomyocyte progenitors in epicardial stem cell niches. J Cell Mol Med 13:866-886

Popescu LM, Manole CG, Gherghiceanu M, Ardelean A, Nicolescu MI, Hinescu ME, Kostin S (2010a) Telocytes in human epicardium. J Cell Mol Med 14:2085-2093

Popescu LM, Gherghiceanu M, Kostin S, Faussone-Pellegrini MS (2010b) Telocytes and heart renewing. In: Wang P, Kuo CH, Takeda N, Singal PK (eds) Adaptation biology and medicine, vol 6. Cell adaptations and challenges. Narosa, New Delhi, pp 17-39

Sakurai S, Hishima T, Takazawa Y, Sano T, Nakajima T, Saito K, Morinaga S, Fukayama M (2001) Gastrointestinal stromal tumors and KIT-positive mesenchymal cells in the omentum. Pathol Int 51:524-531

Schneeberger EE, Lynch RD (2004) The tight junction: a multifunctional complex. Am J Physiol Cell Physiol 286:C1213-C1228

Steed E, Balda MS, Matter K (2010) Dynamics and functions of tight junctions. Trends Cell Biol 20:142-149
Suciu L, Popescu LM, Gherghiceanu M (2007) Human placenta: de visu demonstration of interstitial Cajal-like cells. J Cell Mol Med 11:590-597

Suciu L, Popescu LM, Regalia T, Ardelean A, Manole CG (2009) Epicardium: interstitial Cajal-like cells (ICLC) highlighted by immunofluorescence. J Cell Mol Med 13:771-777

Suciu L, Popescu LM, Gherghiceanu M, Regalia T, Nicolescu MI, Hinescu ME, Faussone-Pellegrini MS (2010) Telocytes in human term placenta: morphology and phenotype. Cells Tissues Organs 192:325-339

Tang VW (2006) Proteomic and bioinformatic analysis of epithelial tight junction reveals an unexpected cluster of synaptic molecules. Biol Direct 1:37. doi:10.1186/1745-6150-1-37

Wuchter P, Boda-Heggemann J, Straub BK, Grund C, Kuhn C, Krause U, Seckinger A, Peitsch WK, Spring H, Ho AD, Franke WW (2007) Processus and recessus adhaerentes: giant adherens cell junction systems connect and attract human mesenchymal stem cells. Cell Tissue Res 328:499-514

Zhou J, Zhang Y, Wen X, Cao J, Li D, Lin Q, Wang H, Liu Z, Duan $\mathrm{C}$, Wu K, Wang C (2010) Telocytes accompanying cardiomyocyte in primary culture: two- and three-dimensional culture environment. J Cell Mol Med 14:2641-2645 